\title{
A Comparison between Forming Behaviours of Two Pre-Consolidated Woven Thermoplastic Composites
}

\author{
N. A. Zanjani, S. Kalyanasundaram \\ Research School of Engineering, ANU College of Engineering and Computer Science, Australian National \\ University, Canberra, Australia \\ Email: nima.akhavan@anu.edu.au
}

Received 26 June 2015; accepted 9 July 2015; published 16 July 2015

\section{Abstract}

This paper presents the results of an investigation on stretch forming behaviour of two consolidated woven thermoplastic composites: a self-reinforced polypropylene (SRPP) and a glass-fibre reinforced polypropylene (GRPP) composite. A custom-built press with a hemispherical punch was employed to deform composites' specimens possessing different aspect ratios into an open die. The induced strains on the outer surface of specimens were measured continuously through two high speed, high resolution CCD cameras by employing a Digital Image Correlation (DIC) technique. The strain paths at three different locations on the surface of specimens were compared to elucidate the effect of fibre and matrix on the formability of a woven composite. The fractured surface of specimens was investigated to reveal the effect of fibre mechanical properties on failure morphologies in woven composites. It was found out that the main mode of failure in GRPP is fibre fracture while observed failure morphologies in SRPP were a complex combination of different failure mechanisms. It was revealed that the combination of applied boundary conditions and specimen's width determines the effective forming mechanisms.

\section{Keywords}

Woven Composite, Stamp Forming, Self-Reinforced Polypropylene, Glass-Fibre Reinforced Polypropylene, Failure

\section{Introduction}

Anthropological climate changes, excessive exploitation of fossil fuels and weight reduction of products are main drivers behind extensive research on finding new material systems. Automotive industry has been continuously cited as one of the major contributors of the human interventions on the environment [1]. The global automotive market, already passed 1 billion fleets in service with an annual increase of 77 million cars, accounts for $40 \%$ of fuel consumptions and $27 \%$ of $\mathrm{CO}_{2}$ emissions worldwide [1] [2]. On average, each car consumes 7 $\mathrm{l} / \mathrm{km}$ petrol and emits $136 \mathrm{~g} / \mathrm{km} \mathrm{CO}$. A weight reduction of $100 \mathrm{~kg}$ results in $5 \%$ saving in fuel consumption and 
4.5\% reduction in $\mathrm{CO}_{2}$ emissions for every $100 \mathrm{~km}$ of transportation [3]. These figures necessitate reducing weight of vehicles by employing lighter material systems to address environmental footprint issues while achieving higher efficiency and cost reduction targets.

Woven Thermoplastic Composite Materials (WTPCMs) offer attractive properties including very low specific density, improved impact resistance, higher fatigue durability and ease of manufacturing [4] [5]. Moreover, they benefit from a unique polymeric structure that allows them to be re-melted and re-shaped after initially consolidated. These properties make them suitable candidates to be employed in the automotive industry to address sustainability and recyclability issues. However, the current manufacturing techniques applied to composites, such as moulding and hand lay-up, has suppressed their widespread application due to the complex and labour-intensive nature of manufacturing processes. Substitution of the current manufacturing techniques with more efficient methods encourages adopting woven composites in mass production industries to address environmental issues and achieve weight reduction targets.

Stamp forming has been extensively studied and applied on metals [6]-[8]. This manufacturing method employs a press equipped with a punch, a die and a blank holder system to deform sheets into desired geometries. Advantages of stamp forming in manufacturing parts include cost-effectiveness, high production rate and precision manufacturing. Although stamp forming of woven prepregs has been studied in numerous works [9]-[11], formability of pre-consolidated WTPCMs, as a current research initiative [12]-[18], still requires extensive investigations. The current article studies stamp forming of two pre-consolidated woven thermoplastic composites: a self-reinforced polypropylene composite and a glass-fibre reinforced polypropylene composite. Specimens possessing different geometries were stamp formed via a hemispherical punch in an open die. Evolution of principal strains and their distributions on the surface of samples were measured through an optical strain measurement system. The strain paths at three different locations were studied to reveal the effect of fibres and the matrix on the forming behaviour of a woven composite. Finally, different fracture morphologies in the two WTPCMs were compared and the underlying causes for this behaviour was discussed and then validated based on force-displacement curves of different specimens.

\section{Experimental Procedures}

\subsection{Materials Systems and Specimen's Geometries}

The two WTPCMs employed in the current study were constituted of an identical matrix reinforced by two different textile materials: a self-reinforced polypropylene composite (SRPP) and a glass-fibre reinforced polypropylene composite (GRPP). Figure 1 illustrates a closed-up view from the structure of the two consolidated blanks made of these two material systems. The textile pattern of both composites was $2 \times 2$ twill weave structure. Both warp and weft yarns in the SRPP structure were straight, however one of the two orthogonal yarns in GRPP composite was curved. The SRPP composite was made by OCV reinforcements Co. [19] from multilayered sheets of two structurally different polypropylene (PP) polymers stacked up together and consolidated via a hot compaction technique developed initially at Leeds University [20]. The GRPP composite, constituted from a single layer fabric of comingled glass fibre (GF) and PP fibre, was manufactured by Owens Corning Co. [21]. The manufacturing process of GRPP included heating up the commingled GF/PP fabric well beyond melting point of the PP fibres followed by cooling down process under low pressure to manufacture consolidated GRPP. A comparison between typical properties of the two woven composites is made in Table 1.

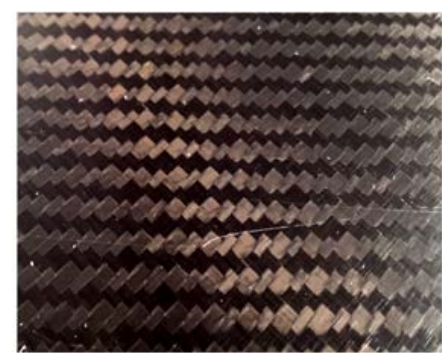

(a) SRPP

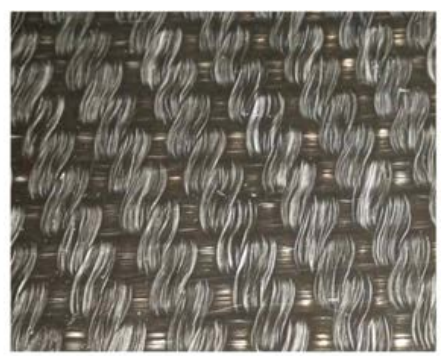

(b) GRPP

Figure 1. SRPP and GRPP specimens. 
Table 1. Comparison between mechanical properties of the two woven composites [16] [18].

\begin{tabular}{ccc}
\hline Mechanical properties & SRPP & GRPP \\
Density $\left(\mathrm{g} / \mathrm{cm}^{3}\right)$ & 0.92 & 1.5 \\
Tensile modulus (GPa) & 4 & 14 \\
Tensile strength (MPa) & 120 & 300 \\
Flexural modulus (GPa) & 3.5 & 12.5 \\
Fibre volume fraction (\%) & - & $55 \%$ \\
\hline
\end{tabular}

\subsection{Geometry of Specimens}

The specimens were cut-out from initially circular $200 \mathrm{~mm}$ in-diameter blanks. The samples' widths (W in Figure 2) varied between $25 \mathrm{~mm}$ to $150 \mathrm{~mm}$ in $25 \mathrm{~mm}$ increments. An additional full circular specimen with 200 mm diameter was made to reveal forming behaviours of the two composites under biaxial stretch. The thickness of all samples was $1 \mathrm{~mm}$. General dimensions of specimens are shown in Figure 2. Each specimen is specified by a CWN parameter in which C specifies the type of WTPCM (S for SRPP and G for GRPP), W is an abbreviation of the Width and $\mathrm{N}$ is a number specifying the width of the sample. For instance, SW50 and GW100 represent a SRPP sample with 50mm width and a GRPP specimen with $100 \mathrm{~mm}$ width, respectively.

\subsection{Experimental Equipment and Procedures}

The samples were initially painted by a stochastic pattern of black dot spray on a white paint background to provide sufficient contrast required for strain measurements. After specimens were dried, they were fixed in an open die system. The die system was composed of upper and lower blank-holders by which the specimens were fully clamped along their circular circumferences through a built-in lock-ring. Then they were deformed until failure by a built-in press with $300 \mathrm{kN}$ capacity equipped with a hemispherical punch. The applied force was measured by a load cell. Dimensions and configuration of the forming equipment are shown in Figure 3.

The displacements and induced strains were continuously measured by two CCD cameras installed beneath the open die (The ARAMIS) [22]. The strain measurement was started from the very early stages of the experiment to capture the effect of lock-ring on the blanks and to measure the induced strains during deformation of samples by the punch until failure. Fractured regions of specimens were examined through an optical microscopy system to elucidate different failure morphologies between SRPP and GRPP woven composites.

\subsection{Deformation Modes in Forming}

In a typical sheet forming practice different forming modes at different locations on the blank are induced. These deformation modes facilitate forming of raw material into desired geometry by incorporating different mechanisms during forming of the samples. It is a common practice to characterise induced deformation modes by the ratio of minor to major strains. Typical forming modes in a stamping process include: 1-Biaxial stretch $(\mathrm{SR}=+1)$ 2-Plane strain $(\mathrm{SR}=0)$ 3-Uniaxial extension $(\mathrm{SR}=-0.5)$ 4-Shear deformation $(\mathrm{SR}=-1)$ 5-Wrinkling $(S R=-2)$. The graphical representation of different strain paths in a strain space is depicted in Figure 4, in which vertical axis represents major strain and horizontal axis depicts minor strain. Generally, the forming path in metals is constant and considered as proportional as it does not experience abrupt changes. However, due to complex internal structure of woven composites, this hypothesis needs to be carefully investigated through experimental observations.

\section{Results and Discussion}

Results of stretch forming experiments on WTPCMs made of different textile reinforcements are discussed in this section. Initially, strain measurements conducted by the 3D photogrammetry system at three points on the surface of $\left[0^{\circ}, 90^{\circ}\right]$ specimens are presented. The locations of these points are depicted in Figure 5. The Pole is located at the intersection of horizontal and vertical symmetry axes of specimens, P1 is located X mm further from the pole on the warp (longitudinal) fibres and P2 is located X mm away from the pole along the $45^{\circ}$ orien- 


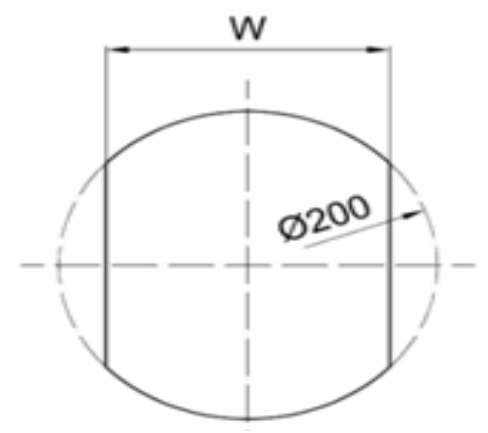

Figure 2. Dimensions of woven composite specimens.

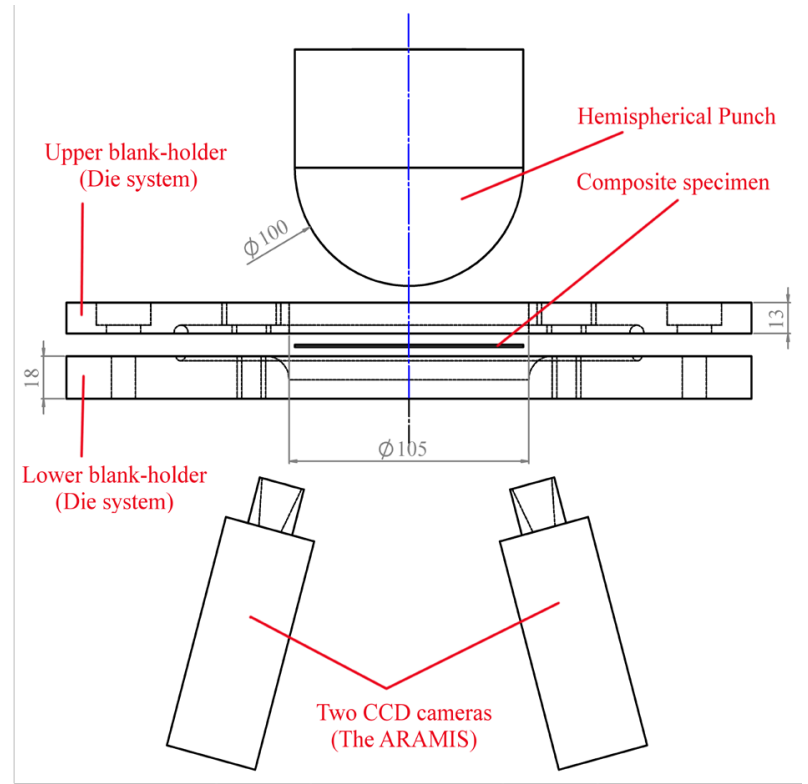

Figure 3. Configuration of stretch forming equipment and measurement system.

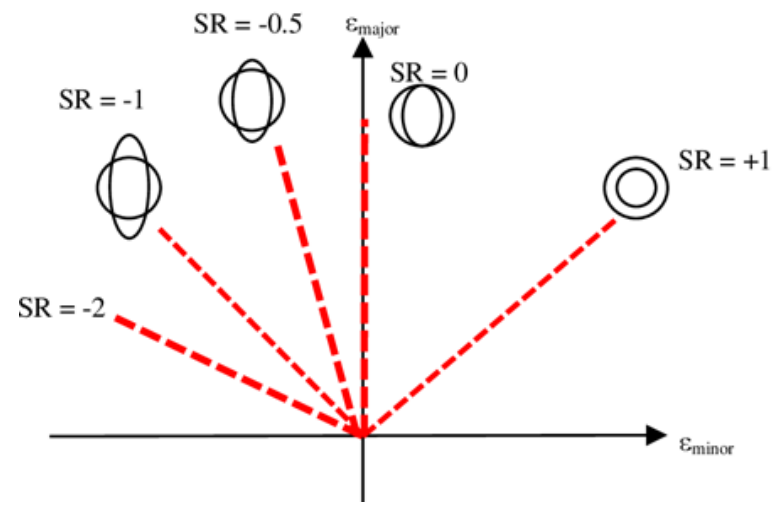

Figure 4. Main deformation modes during sheet forming.

tation. The value of X, dependent to the sample's width, is mentioned later. These points are representative of different forming behaviours of a WTPCM at different regions specified by different contact evolution, fibre extension and shear behaviour and therefore elucidate formability of a pre-consolidated woven composite under different deformation modes. 


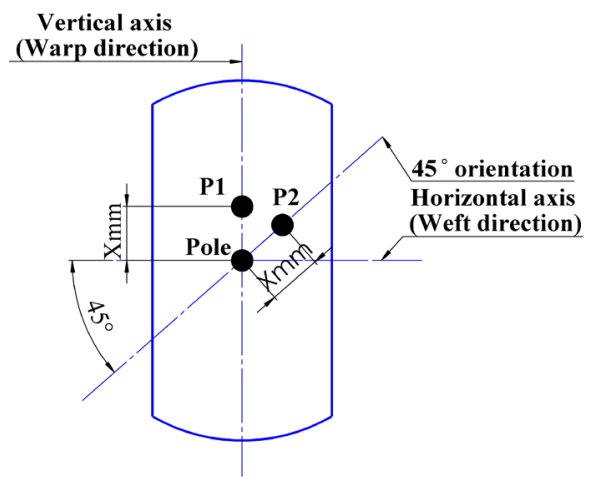

Figure 5. Points of interest on WTPCM specimen.

\subsection{Strain Path at Points of Interests}

It is beneficial to examine different stages of deformations based on the contact conditions between samples and the punch and to correlate between the evolution of strain path at the pole and the depth of deformation induced by a hemispherical punch. Generally, three stages of deformation during stretch forming of a woven composite can be distinguished (Figure 6).

1-Lock-ring effect (edge-effect): This stage is caused by the lock-ring system during clamping of specimens. The gradient of the strain path and therefore the induced deformation mode is a function of specimen's width and the materials Poisson's ratio. In narrow samples, the induced deformation mode is near to uniaxial extension and in the widest sample it is close to biaxial stretch. The induced principal strains in this stage are very low compared to the total strains induced by the punch due to comparatively low clamping torque applied to specimens. 2-Initial contact: The mode of deformation induced in this stage is a function of specimen's aspect ratio and the material's stiffness. In a woven composite with a relatively low stiffness (compared to metals), the induced mode of deformation is near to biaxial stretch due to the localised contact between punch and the blank, identical extension of both warp and weft yarns and the highly localised deformation and strain concentration during contact with a hemispherical punch. 3-Final contact: At this stage, the biaxial stretch mode disappears and the sample's specific deformation mode, determined by the specimen's aspect ratio and the punch geometry, governs its forming behaviour. Due to the enforced boundary condition, the contact surface between the specimen and the punch along warp and weft directions are not identical and therefore friction force along warp is more than of weft direction. However, increase of the forming depths results in a similar contact surface along the two orthogonal directions and therefore causes a gradual shift in the induced deformation mode leading to failure. This point is depicted by point $C$ in Figure 6. Another factor, changing strain path after point $C$, is the evolution of material properties by the applied strains. Figure 6 illustrates these stages of deformation in the strain path of a typical WTPCM.

To represent different forming behaviours of SRPP and GRPP specimens, three specimens from each group is selected: SW25, SW75, SW150, GW25, GW75 and GW150. It will be shown that a change in specimen's width alters the deformation mode under which the material fails (deformation mode in final stage of deformation). This behaviour is caused by a combination of different phenomena: Larger specimens, possessing bigger mass, have enough material to deform into the die cavity and therefore can potentially sustain larger forming depths. However, increase in the width of samples causes the ratio of clamped length to the total circumference of the sample enlarges and therefore the forming depths decrease due to the enforced boundary condition. The synergy between these two factors makes a balance between draw and stretch behaviours of samples and therefore determines the forming depth at which specimens fracture. Three different points on the surface of each SRPP and GRPP specimens were selected to study behaviour of these materials under different forming mechanisms: Pole, $\mathrm{P} 1$ and P2 (Figure 5). In this figure, $\mathrm{X}$ is equal to $10 \mathrm{~mm}$ in W25 samples and 30mm in larger specimens. Pole is located at the intersection of two symmetry axes of the specimens where warp and weft yarns intersect and therefore determines the forming limits of the material under the influence of both orthogonal yarns. The behaviour of specimens at P1 is mainly influenced by the extension of the longitudinal (warp) yarns and P2 exhibits the specimen's formability under combined matrix shearing and fabric trellising mechanisms. Figures 7-9 com- 


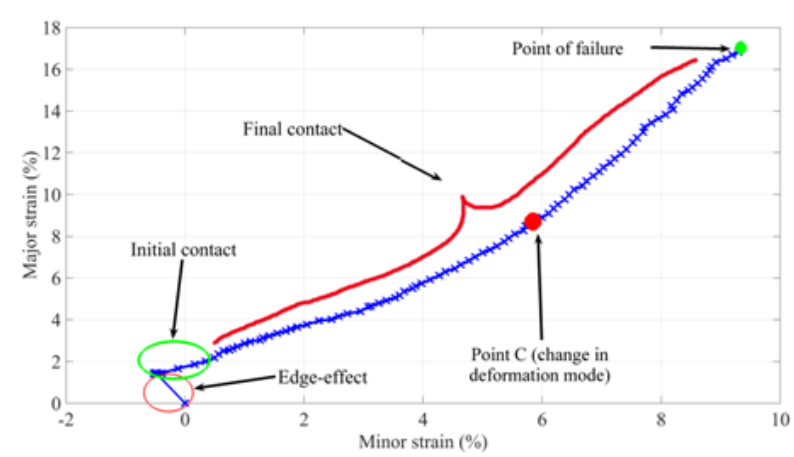

Figure 6. Different stages of deformation during stretch forming of a woven composite (SW150).

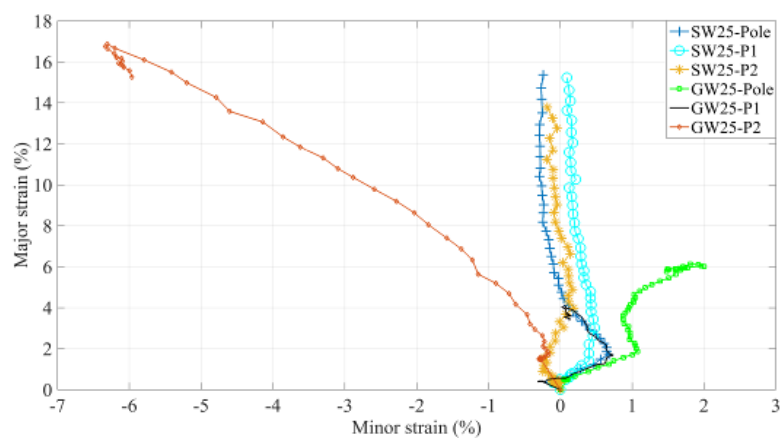

Figure 7. Induced principal strains on SW25 and GW25 specimens.

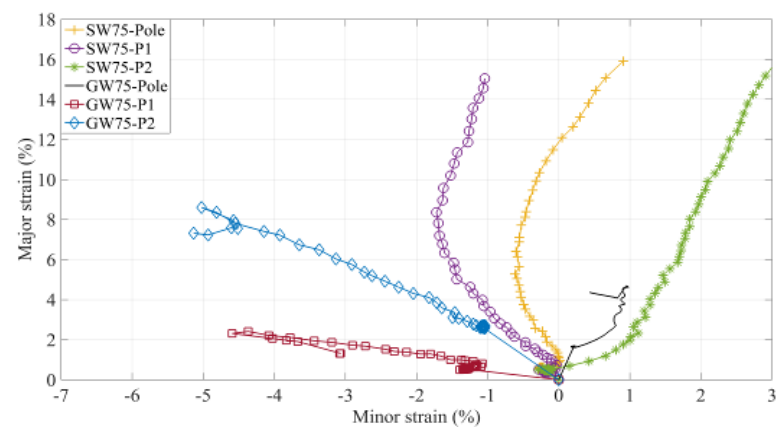

Figure 8. Induced principal strains on SW75 and GW75 specimens.

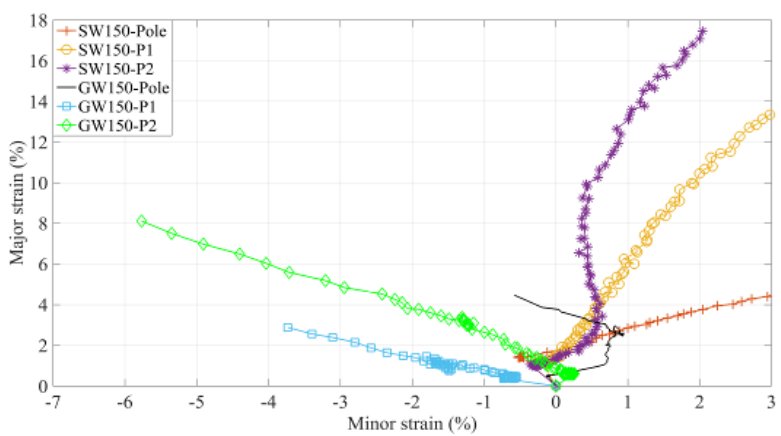

Figure 9. Induced principal strains on SW125 and GW125 specimens. 
pare forming behaviours of the two material systems at different depths of deformation in specimens possessing $25 \mathrm{~mm}, 75 \mathrm{~mm}$ and $150 \mathrm{~mm}$ widths, respectively.

In Figure 7, all three surface points of SW25 exhibit near to uniaxial extension mode, followed up by a near to biaxial stretch mode during the lock-ring and initial contact stages of deformation. The final deformation modes is located between uniaxial extension and plane strain modes, dictated by the contact between punch and the sample counteracting Poisson's effect in inducing negative minor strain along weft (transverse) direction. The similarity between induced strain ratios at these three locations elucidates the insensitivity of the deformation mode in these SRPP specimens to the location. However, in the GRPP composite, the location of the points shows a significant effect on the induced strain path. The final deformation mode at the pole initially follows a uniaxial extension path which is abruptly changed to biaxial stretch. This behaviour is specific to woven composites reinforced with highly inextensible, brittle fibres: increase of punch penetration rises the contact pressure between the blank and the punch leading to sudden localised fracture of glass fibres at the pole which changes the strain path. However, at point P1, this behaviour is not observed due to a decreased contact pressure between the blank and the punch at this location. At point P2, excessive shearing of the fabric (trellising) causes the strain path at GW25-P2 to follow shear deformation mode. The dissimilar strain path at point P2 in SRPP and GRPP specimens profoundly highlights the fundamental differences between manufacturing processes of the two composites and the different interface properties between fibres and the matrix leading to dissimilar mechanical behaviours of the two woven composites.

The W75 specimens show completely different forming behaviours, compared to W25 samples, as a result of having different aspect ratios (Figure 8). This is due to a completely different trend in the evolution of contact surface between punch and specimens, resulting in a more distinguished difference between strain path at the pole, P1 and P2. However, the gradient of the strain path at the final stage of deformation for the three points on SW75 specimens is similar, in contrast to GW75 specimens, re-emphasizing the fundamental differences between the structures of the two WTPCMs.

All points on SW150 specimens show a biaxial stretch mode at the final stage of the deformation due to the applied boundary conditions and specimens' widths (Figure 9). However, in GW150 sample, the pole shows a near to biaxial stretch mode until onset of localised fracture of glass fibres, while points P1 and P2 depict shear deformation mode. However, point P2 shows much higher strains compared to all other points due to excessive trellising of the glass-fibres, delaying the initiation of fracture in GRPP composite by hampering fibre extension.

\subsection{Fracture of SRPP and GRPP Composites during Stretch Forming}

Different strain paths and their evolutions in the two WTPCMs depict different formability characteristics of these material systems under stretch forming conditions. This is resulted from different reinforcements, dissimilar matrix-fibre interface and manufacturing processes applied to the two composites. In this section, the effects of these parameters on failure morphologies of the two composites are investigated. Figure $\mathbf{1 0}$ and Figure $\mathbf{1 1}$

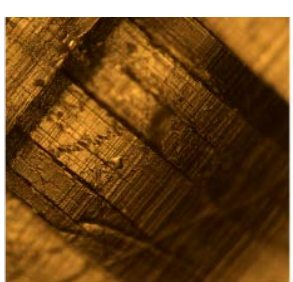

SW25

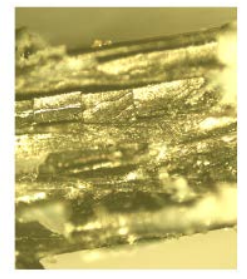

SW25

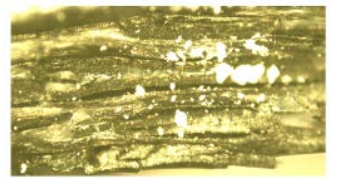

SW25

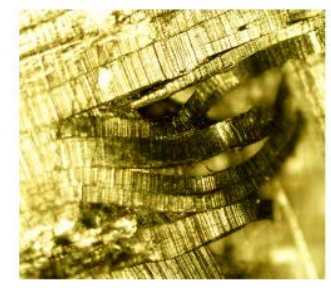

SW150

Figure 10. Failure morphologies in SRPP specimens. 


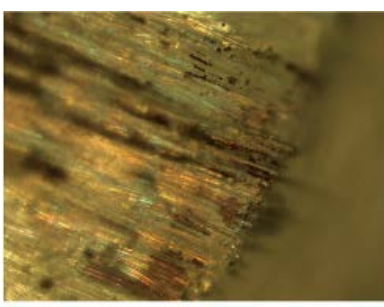

GW25

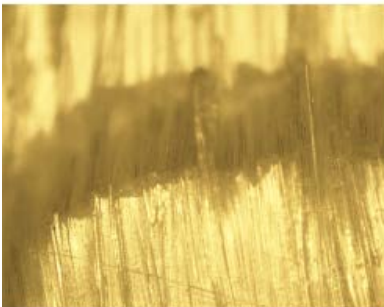

GW150

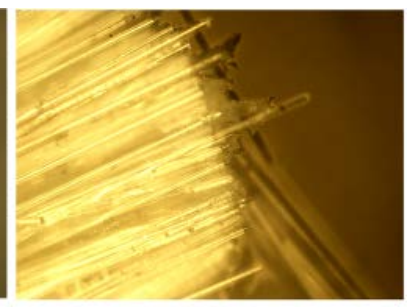

GW150

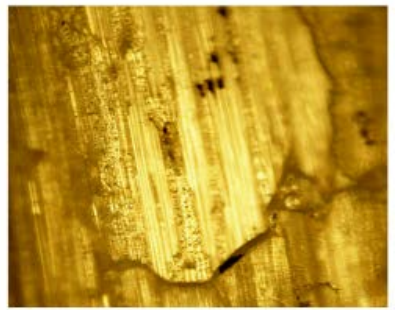

GW150

Figure 11. Failure morphologies in GRPP specimens.

reveal optical microscopy results on two typical SRPP and GRPP samples, respectively. Longitudinal crack growths and rupture of the yarns are observed in SRPP specimens. These phenomena show mode I of fracture or tensile opening at the matrix-fibre interface. Delamination is another dominant failure mode in SRPP specimens. Matrix thinning is also observed which can be regarded as a pseudo-plastic behaviour of the material. Transverse cracks are developed through the thickness of the SRPP specimens. At some locations, fibre kinking is also observed due to highly localised compressive strains.

On the other hand, the dominant failure mode in GRPP specimens is fibre fracture. The even fractured surface of these specimens shows that fibre pull-out due to yielding of the material at the fibre-matrix interface has not occurred and the failure sites predominantly exhibit a rough fractured surface on the GRPP composite due to its brittle nature. Fracture is caused by inextensibility of glass fibres and its brittle behaviour. These microscopy images show different failure mechanisms of the two WTPCMs: The SRPP failure is more complex than GRPP as a result of complex interactions between reinforcement and the matrix, their identical mechanical properties and fusion of fibres and the matrix at their interface. However, in a GRPP composite, inextensibility of glass fibres and completely different mechanical properties of the reinforcement and the matrix makes the fibre fracture to be the main reason of the failure. However, the strain path evolution of GRPP specimens reveals the gradual onset of failure during conformity of the samples to the punch.

Studying force-displacement graphs of the two WTPCMs during stamping reveals the fundamental differences between the responses of these material systems to out-of-plane loading and re-emphasizes on the previous assumptions on failure mechanisms of the two composites based on microscopy observations. Figure 12 represents stamping force (in $\mathrm{kN}$ ) versus depth of deformation (in $\mathrm{mm}$ ) of three different SRPP and GRPP specimen until failure. Depth of deformation for SRPP is generally twice as of GRPP composite, resulted from high extensibility PP polymer fibres.

The force-displacement of SRPP shows a smooth, exponentially increasing trend with a gradual increase in the material's resistance to deform further. This behaviour can be related to the woven structure of the composite in which the orthogonal yarns support each other during application of external loadings and the internal friction between these yarns increases as the contact pressure between punch and the blank rises. A sudden drop in force at the final stage of deformation is observed which indicates the catastrophic failure of the SRPP composite. The aspect ratio of the SRPP composite does not affect the final depth of deformation drastically. The GRPP response to external loadings is completely different: the aspect ratio greatly affects the forming depth highlighting the stronger support of orthogonal yarns during stamping. The narrowest sample (GW25) deforms up to the depth 15mm, while the largest GRPP specimen (GW150) deforms twice of GW25. Secondly, the recurrent decrease in the slope of force-displacement curve indicates the gradual fracture of the glass-fibres and re-validates the precious assumption on the main cause of fracture in GRPP composite during stamp forming. 


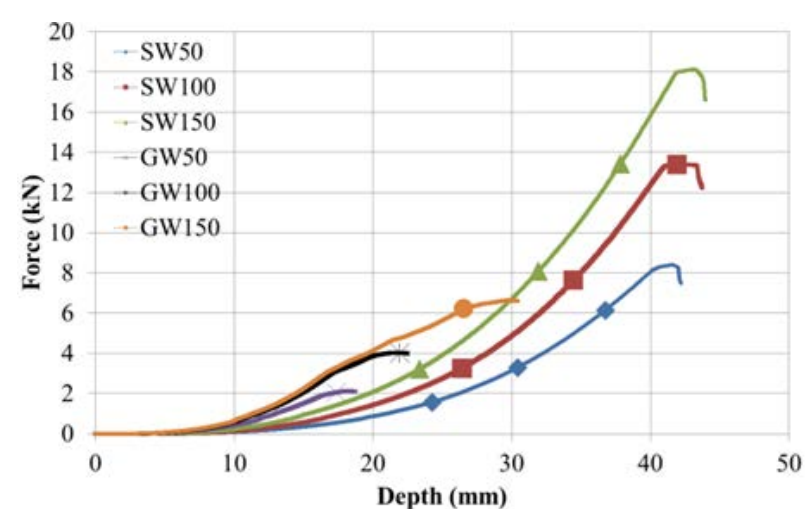

Figure 12. Comparison between force-displacement curve of two WTPCMs during forming.

\section{Conclusions}

Specimens of two consolidated woven composites possessing different aspect ratios were stretch formed with a hemispherical punch. The induced deformations were measured through a 3D photogrammetry system and the strains were calculated. Comparison between strain paths at different locations on samples revealed the following fundamental differences between stamp-forming behaviours of the two composites:

- Higher sensitivity of strain ratio and therefore induced deformation modes to the location in GRPP composite compared to SRPP composite.

- Significant higher formability of GRPP composite under shear deformation mode.

- Pure trellising of GRPP at $\pm 45^{\circ}$ directions compared to more matrix shearing in SRPP.

- Catastrophic failure of SRPP compared to gradual and localised fibre fracture of GRPP.

- The combination of specimen's width and applied boundary condition is a determinant factor on the formability of a woven composite.

The optical microscopy examination on the site of failure revealed the main cause of failure in GRPP composite is fibre fracture while failure phenomena in SRPP composite is a complex mixture of different mechanisms including fibre pull-out, shearing of the matrix and delamination. The different failure behaviours of the two WTPCMs were well reflected in their force-displacement curves, re-emphasizing the effect of reinforcements' mechanical properties on the failure mechanism of a woven composite. The investigations on forming of the two consolidated woven composites show their great potential to be formed into different geometries through stamping process and therefore to be employed in producing cost-effective, mass produced components.

\section{References}

[1] Kastensson, G.A. (2014) Developing Lightweight Concepts in the Automotive Industry: Taking on the Environmental Challenge with the SåNätt Project. Journal of Cleaner Production, 66, 337-346. http://dx.doi.org/10.1016/j.jclepro.2013.11.007

[2] Mayyasa, A., Qattawia, A., Omara, M. and Shana, D. (2012) Design for Sustainability in Automotive Industry: A Comprehensive Review. Renewable and Sustainable Energy Reviews, 16, 1845-1862. http://dx.doi.org/10.1016/j.rser.2012.01.012

[3] International Council of Clean Transportation (ICCT) (2013) Reducing $\mathrm{CO}_{2}$ and Fuel Consumption from New Cars: Assessing the Near-Term Technology Potential in the EU. http://www.theicct.org

[4] Reyes, G. and Sharma, U. (2010) Modeling and Damage Repair of Woven Thermoplastic Composites Subjected to Low Velocity Impact. Composite Structures, 92, 523-531. http://dx.doi.org/10.1016/j.compstruct.2009.08.038

[5] Karakuzua, R., Aslanb, Z. and Okutan, B. (2004) The Effect of Ply Number, Orientation Angle and Bonding Type on Residual Stresses of Woven Steel Fiber Reinforced Thermoplastic Laminated Composite Plates Subjected to Transverse Uniform Load. Composites Science and Technology, 64, 1049-1056. http://dx.doi.org/10.1016/j.compscitech.2003.09.014

[6] Keeler, S.P. (1990) Automotive Sheet Metal Formability. National Steel Corporation, Product Application Center, Technical Report AU 89-1. 
[7] Tekkaya, A.E. (2000) State-of-the-Art of Simulation of Sheet Metal Forming. Journal of Materials Processing Technology, 103, 14-22. http://dx.doi.org/10.1016/S0924-0136(00)00413-1

[8] Makinouchi, A. (1996) Sheet Metal Forming Simulation in Industry. Journal of Materials Processing Technology, 60, 19-26. http://dx.doi.org/10.1016/0924-0136(96)02303-5

[9] Van West, B.P., Byron Pipes, R., Keefe, M. and Advani, S.G. (1991) The Draping and Consolidation of Commingled Fabrics. Composites Manufacturing, 2.

[10] Badel, P., Gauthier, S., Vidal-Sallé, E. and Boisse, P. (2009) Rate Constitutive Equations for Computational Analyses of Textile Composite. Composites: Part A, 40, 997-1007. http://dx.doi.org/10.1016/j.compositesa.2008.04.015

[11] Sargent, J., et al. (2010) Benchmark Study of Finite Element Models for Simulating the Thermostamping of WovenFabric Reinforced Composites. International Journal of Material Forming, 3, 683-686. http://dx.doi.org/10.1007/s12289-010-0862-5

[12] Zanjani, N.A. and Kalyanasundaram, S. (2015) Induced Forming Modes in a Self-Reinforced Polypropylene Sheet during Stretch Forming Process at Room Temperature: I-Experimental Studies. Composites Part A, 68, 251-263. http://dx.doi.org/10.1016/j.compositesa.2014.09.023

[13] Zanjani, N.A., Wang, W. and Kalyanasundaram, S. (2015) The Effect of Fibre Orientation on the Formability and Failure Behaviour of a Woven Self-Reinforced Composite during Stamp Forming. ASME Journal of Manufacturing Science and Engineering, in Press.

[14] Wang, W., Lowe, A., Davey, S., Zanjani, N.A. and Kalyanasundaram, S. (2015) Establishing a New Forming Limit Curve for a Flax Fibre Reinforced Polypropylene Composite through Stretch Forming Experiments. Composites Part A, in Press. http://dx.doi.org/10.1016/j.compositesa.2015.06.021

[15] Davey, S., Das, R., Cantwell, W.J. and Kalyanasundaram, S. (2013) Forming Studies of Carbon Fibre Composite Sheets in Dome Forming Processes. Journal of Composite Structures, 97, 310-316. http://dx.doi.org/10.1016/j.compstruct.2012.10.026

[16] Compston, P., Cantwell, W.J., Cardew-Hall, M.J., Kalyanasundaram, S. and Mosse, L. (2004) Comparison of Surface Strain for Stamp Formed Aluminium and Aluminium-Propylene Laminate. Journal of Material Science, 39, 60876088. http://dx.doi.org/10.1023/B:JMSC.0000041707.68685.72

[17] Kalyanasundaram, S., Dhar Malingam, S., Venkatesan, S. and Sexton, A. (2012) Effect of Process Parameters during Forming of Self-Reinforced PP-Based Fibre Metal Laminates. Composite Structures, 97, 332-337. http://dx.doi.org/10.1016/j.compstruct.2012.08.053

[18] Mosse, L., Compston, P., Cantwell, W.J., Cardew-Hall, M.J. and Kalyanasundaram, S. (2006) Stamp Forming of Polypropylene Based Fibre-Metal Laminates: The Effect of Process Variables on Formability. Journal of Materials Processing Technology, 172, 163-168. http://dx.doi.org/10.1016/j.jmatprotec.2005.09.002

[19] CV Reinforcement Co. www.ocvreinforcements.com

[20] Ward, I.M. and Hine, P.J. (2004) The Science and Technology of Hot Compaction. Journal of Polymer, 45, $1413-1427$. http://dx.doi.org/10.1016/j.polymer.2003.11.050

[21] Owens Corning Co http://fiberglassindustries.com

[22] GOM mbH. www.GOM.com 